\title{
Effect of dry needling on submaximal strength and pain in patients with active myofascial trigger points in the rectus femoris: A case series
}

\author{
María Pilar López Royo ${ }^{1}$ Carolina Jiménez Sánchez ${ }^{10}$ \\ ${ }^{1}$ Grupo de Investigación iPhysio, Facultad de Ciencias de la Salud, \\ Universidad San Jorge, Villanueva de Gállego, Zaragoza, Spain \\ Address for correspondence María Pilar López Royo, MSc, Facultad de \\ Ciencias de la Salud, Universidad San Jorge, Autovía A23, km 299, \\ 50830, Villanueva de Gállego, Zaragoza, España \\ Rev Fisioter Invasiva 2020;3:35-37. \\ (e-mail: mplopez@usj.es).
}

\begin{abstract}
Keywords

- myofascial trigger point

- dry needling

- femoral rectus

A myofascial trigger point (MTrP) is a hyperirritable area of a skeletal muscle, of nodular appearance on palpation and located in a taut band. One of the techniques for the treatment of MTrP is dry needling (DN). The aim of the present work was to determine whether treatment with DN is effective in terms of pain relief and improvement of muscle weakness. For this purpose, differences in the Visual Analog Scale (VAS) and the Brzycki Test were observed before and after treatment of an active MTrP of the rectus femoris. In total, 5 patients received the treatment, of which $80 \%$ showed an improvement in pain and an increase in submaximal strength. Although it is not possible to establish a causal relationship, the results appear consistent with our hypothesis that $\mathrm{DN}$ is able to generally improve the symptoms of pain and weakness that appeared in patients.
\end{abstract}

\section{Introduction}

A myofascial trigger point (MTrP) is a hypersensitive area of a skeletal muscle with a nodular appearance upon palpation, which is located on a taut band. ${ }^{1}$ Considering the clinical characteristics of MTrPs, they can be classified as active or latent. A latent MTrP is a sensitive spot with pain that is only felt in response to different types of stimulation, although maintaining other typical characteristics, such as the appearance of a taut band and limitation of the range of movement. In contrast, an active MTrP is a spot that is characterized by a local spontaneous and/or mechanical and/or referred pain that is provoked by movement, compression or stretching. ${ }^{1}$

Many health professionals have recognized MTrPs as the most common cause of pain and dysfunction within the musculoskeletal system. ${ }^{1}$ They can affect $85 \%$ of the general population, with a prevalence that varies between $30 \%$ and 93\%; this variation is explained by the fact that there is no consensus on the diagnostic criteria. ${ }^{2,3}$

Muscle dysfunction generated by MTrPs is characterized, among other aspects, by shortening, weakness, fatigue, dis- coordination and own and referred inhibition, characteristics that tend to be of greater magnitude in active MTrPs. ${ }^{4}$

For the treatment of MTrPs, one of the techniques most used by physiotherapists is dry needling (DN). The American Physical Therapy Association (APTA) has defined DN as a "skillful intervention using a thin filiform needle to penetrate the skin and stimulate underlying MTrPs, muscular and connective tissues for the management of neuromusculoskeletal impairments". ${ }^{5}$

For an invasive technique to be effective for the treatment of MTrPs, profound knowledge of the anatomy is essential, together with the ability to identify trigger points through palpation, as well as an exquisite skill in the identification of the MTrP. The exact location of the MTrP, the precision in the use of DN, as well as the ability to elicit local twitch responses (LTRs) are essential for its effectiveness, especially during the deep dry needling (DDN) techniques, in which the needle goes through the MTrP.,

Considering that the weakness of some muscles can be related to the appearance of a MTrP, whether latent or active, it is necessary to assess muscle strength as well as the perceived level of pain after treatment with DN. Therefore, received

November 7, 2019

accepted

November 22, 2019
DOI https://doi.org/

10.1055/s-0040-1701290. ISSN 2386-4591.
Copyright $(2020$ by Thieme Revinter

Publicações Ltda, Rio de Janeiro, Brazil
License terms

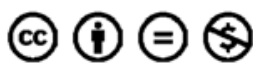


the aim of the present study was to evaluate the effect of DDN regarding pain and submaximal muscle strength of the rectus femoris in people with one or more active MTrPs in this muscle.

\section{Material and Methods}

\section{Design}

A prospective case series study was performed, in which the submaximal strength of the rectus femoris was quantified together with the subjective perception of pain before and after the performance of the DDN technique. The present study was performed following the Case Report (CARE) clinical practice guidelines. ${ }^{8}$

\section{Population}

The sample was recruited from a sports center in Zaragoza, Spain. The subjects had to fulfil the following inclusion criteria: presenting an active MTrP in the rectus femoris with referred pain to the area of the patella, being physically active, and having signed the informed consent form. The present study excluded subjects who had suffered a previous lesion in the muscle assessed, those who had undergone invasive physical therapy treatment during the three months prior to the study and/or regular pharmacological treatment during the previous month, and individuals with needle phobia.

\section{Procedure}

Initially, participants were explained the purpose of the study, and they were given a brief introduction on the physiology of MTrPs and the DDN technique. Two physical therapists were involved in the study. One physical therapist assessed the pain and submaximal strength values both preand post-treatment, whereas a second physical therapist was in charge of performing the intervention.

Prior to the assessment and intervention, a muscle warmup was performed on a static bicycle during 10 minutes, with a minimum resistance of 1 .

\section{Assessment}

To evaluate the submaximal strength of the rectus femoris, the Brzycki test was used, which is based on the number of repetitions lifting submaximal weight that one can perform before fatigue. Based on this information, the submaximal weight that a person can correctly move in one repetition is calculated using the following formula: 1 Repetition Maximum (1 RM) = total displaced load $(\mathrm{Kg}) /$ Brzycki index.

This test was performed on the quadriceps bench (Selection Quadriceps Extension, Technogym, Cesena, ForlìCesena, Italy) due to the associated ease to maintain the correct posture, avoiding compensations, as well as the possibility of performing a unilateral evaluation. The participants were asked to perform the test (maximum of 15 repetitions) with an estimated weight for each person until the resistance offered was impossible to bear. The total displaced weight was recorded, as well as the number of repetitions, to calculate the Brzycki index and the 1RM.
In addition, before and after the DDN was performed, the Visual Analog Scale (VAS) was used, and the participants were asked to quantify their pain from 0 to 10 , with 0 meaning absence of pain, and 10 , the maximum bearable pain. A change of two points on this scale is considered clinically significant. ${ }^{9}$

\section{Intervention}

The patients were placed in supine position on the treatment table with a wedge below the lower limb to enable $30^{\circ}$ of hip flexion, $30^{\circ}$ of knee flexion and a slight external hip rotation of $\sim 15^{\circ}$. The intervention consisted of one session of DDN on the active MTrP of the rectus femoris. This MTrP is commonly found between $10 \mathrm{~cm}$ and $15 \mathrm{~cm}$ below the anteroinferior iliac spine, presenting a pattern of referred pain toward the knee, the patella and around this area. ${ }^{10}$ The MTrPs were identified by palpation of the rectus femoris muscle, which was performed perpendicular to the muscle fibers. A physical therapist trained in locating MTrPs performed the physical exam. The DDN technique was applied using needles (Agupunt, Barcelona, Catalonia, Spain) with a guide tube measuring $0.30 \times 6 \mathrm{~cm}$. The area was previously cleaned and disinfected using an antiseptic solution (70\% propan-2-ol, Skin-des, Antiseptica, Pulheim, North Rhine-Westphalia, Germany). The technique used for the DDN was the fast-in and fast-out technique with multiple insertions, as described by Chou et al, ${ }^{11}$ which consists of the insertion of the needle quickly up and down, without rotating it, in the area of the MTrP to achieve as many LTRs as possible within the tolerance level of each patient.

\section{Results}

The sample comprised 2 men and 3 women, whose ages ranged between 21 and 42 years.

Regarding the assessment of submaximal strength of the rectus femoris, the results obtained are shown in - Table $\mathbf{1}$, with a mean of $35.70 \mathrm{~kg}$. The final mean weight was $39.32 \mathrm{~kg}$, with an increase of $3.62 \mathrm{~kg}$. Up to $80 \%$ of the patients increased their submaximal strength compared with the first assessment. Only 1 subject, participant 4, did not obtain any improvement in the submaximal knee extension strength (-Table $\mathbf{1}$ ).

The participants underwent a pain assessment based on the VAS before ( 6.2 points) and after ( 4.2 points) the application of the DDN technique. Up to $80 \%$ of the participants showed a reduction of 2.5 points on the VAS regarding pain after the

Table 1 Results for submaximal strength (in kilos)

\begin{tabular}{|l|l|l|}
\hline Participants & Preintervention & Postintervention \\
\hline 1 & 35.23 & 36.84 \\
\hline 2 & 26.67 & 32.74 \\
\hline 3 & 33.88 & 36.83 \\
\hline 4 & 46.68 & 45.00 \\
\hline 5 & 36.00 & 45.18 \\
\hline
\end{tabular}


Table 2 Results for the perceived level of pain on the Visual Analog Scale

\begin{tabular}{|l|l|l|}
\hline Participants & Preintervention & Postintervention \\
\hline 1 & 7 & 4 \\
\hline 2 & 8 & 6 \\
\hline 3 & 4 & 2 \\
\hline 4 & 6 & 6 \\
\hline 5 & 6 & 3 \\
\hline
\end{tabular}

application of DDN, whereas 1 subject (participant 4) did not experience changes after the intervention ( $\mathbf{- T a b l e ~} \mathbf{2}$ ).

\section{Discussion}

The aim of the present case series was to describe changes in the level of submaximal muscle strength and pain immediately after a session of DDN on the rectus femoris.

The findings suggest that DDN may increase the submaximal strength in the short term after a single session. These findings contrast with a recent meta-analysis ${ }^{12}$ that concluded that a large number of the studies performed in the region of the thigh and knee do not show changes in muscle strength immediately after the application of DN. Further studies are required to clarify the specific effect of DDN on the improvement in muscle strength in the short, mid and long terms.

Our results indicate a beneficial effect regarding pain quantified using the VAS scale in $80 \%$ of the participants, considering that a change of 2 points on this scale is considered clinically significant. ${ }^{9}$ According to the available literature, the best technique for the total and immediate inactivation of MTrPs is the technique of rapid needle insertions, which has obtained satisfactory results for the elimination of pain immediately after application. ${ }^{11}$ In a case series $^{13}$ on cubital tunnel syndrome, improvements were observed regarding the reduction of pain in the second DDN session compared with our study; therefore, DN is thought to act according to the gate control theory, supporting the liberation of endogenous opioids.

The present study has several limitations worth noting. One of the limitations concerns the size of the sample, as only participants who fulfilled the selection criteria during the recruitment period were included. Furthermore, the study lacked a control group. Another limitation is the number of DDN sessions, considering that, although we sought to evaluate possible changes in strength and pain after a single session, this may be insufficient for the deactivation of the MTrPs of the rectus femoris; therefore, the results obtained regarding submaximal muscle strength and pain could be largely modified with further DDN sessions. Moreover, by performing further sessions, we could have assessed the extent to which adding more sessions may offer additional improvements. Lastly, it is necessary to perform assessments in the mid and long term, to enable follow-up, as well as the use of an isokinetic dynamometry device to ensure a more controlled assessment and intervention.

\section{Conclusion}

Although it is not possible to establish a causal relationship, the results of the present case study showed that $80 \%$ of the participants treated with DDN of active MTrPs in the rectus femoris improved their submaximal muscle strength and pain. Future research is required with larger samples to verify the effect of DDN in patients with active MTrPs in the rectus femoris.

Conflict of Interests

The authors have no conflict of interests to declare.

\section{References}

1 Simons DG, Travell JG, Simons LS. Dolor y disfunción miofascial. El manual de los puntos gatillo. Volumen 1. Mitad superior del cuerpo. $2^{\text {a }}$ edición. Editorial Médica Panamericana; 2005

2 Fleckenstein J, Zaps D, Rüger LJ, et al. Discrepancy between prevalence and perceived effectiveness of treatment methods in myofascial pain syndrome: results of a cross-sectional, nationwide survey. BMC Musculoskelet Disord 2010;11:32. Doi: 10.1186/1471-247411-32

3 Saxena A, Chansoria M, Tomar G, Kumar A. Myofascial pain syndrome: an overview. J Pain Palliat Care Pharmacother 2015; 29(01):16-21. Doi: 10.3109/15360288.2014.997853

4 Shah JP, Thaker N, Heimur J, Aredo JV, Sikdar S, Gerber L. Myofascial Trigger Points Then and Now: A Historical and Scientific Perspective. PM R 2015;7(07):746-761. Doi: 10.1016/j.pmrj.2015.01.024

5 Fernández-de-Las-Peñas C, Nijs J. Trigger point dry needling for the treatment of myofascial pain syndrome: current perspectives within a pain neuroscience paradigm. J Pain Res 2019;12:1899-1911. Doi: $10.2147 / J P R . S 154728$

6 Mayoral O. Fisioterapia invasiva del síndrome de dolormiofascial. Fisioterapia 2005;27:69-75

7 Dommerholt J. Dry Needling in Orthopaedic Physical Therapy Practice. Orthop Phys Ther Practice 2004;16(03):11-16

8 Gagnier JJ, Kienle G, Altman DG, Moher D, Sox H, Riley D; CARE Group*. The CARE Guidelines: Consensus-based Clinical Case Reporting Guideline Development. Glob Adv Health Med 2013; 2(05):38-43

9 Gattie E, Cleland JA, Snodgrass S. The Effectiveness of Trigger Point Dry Needling for Musculoskeletal Conditions by Physical Therapists: A Systematic Review and Meta-analysis. J Orthop Sports Phys Ther 2017;47(03):133-149. Doi: 10.2519/jospt.2017.7096

10 Simons DG, Travell JG, Simons LS. Dolor y disfunción miofascial. El manual de los puntos gatillo. Volumen 2. Extremidades inferiores. $2^{\mathrm{a}}$ edición. Editorial Médica Panamericana; 2005

11 Chou LW, Hsieh YL, Kuan TS, Hong CZ. Needling therapy for myofascial pain: recommended technique with multiple rapid needle insertion. Biomedicine (Taipei) 2014;4(02):13. Doi: 10.7603/s40681-014-0013-2

12 Mansfield CJ, Vanetten L, Willy R, di Stasi S, Magnussen R, Briggs $M$. The effects of needling therapies on muscle force production: a systematic review and meta-analysis. J Orthop Sports Phys Ther 2019;49(03):154-170. Doi: 10.2519/jospt.2019.8270

13 Anandkumar S, Manivasagam M. Effect of dry needling on cubital tunnel syndrome: Three case reports. Physiother Theory Pract 2019;35(04):363-372. Doi: 10.1080/09593985.2018.1449275 